\title{
STRUCTURAL AND VIBRO-ACOUSTIC ANALYSES OF A SPACE CAPSULE
}

\author{
Rakhesh G. B ${ }^{1}$, B. Balakrishnan ${ }^{2}$, S. Raja ${ }^{3}$, K. Badari Narayana ${ }^{4}$ \\ ${ }^{I}$ M.Tech Student, Department of Mechanical Engineering, BMSIT \& M. Bengaluru, India \\ rgoggad@gmail.com \\ ${ }^{2,3}$ Scientist, $2 \nmid$ Sr. Principal Scientist, STTD, CSIR-National Aerospace Laboratories Bengaluru, India \\ ${ }^{4}$ Professor, Department of Mechanical Engineering, BMSIT \& M. Bengaluru, India
}

\begin{abstract}
In the present numerical study, manned space capsule is designed and conceptualized for gravitational and acoustic loads. The preliminary study involves design, CAD model building, developing of finite element model and simulation of gravity and acoustic loads. Use of advanced materials in the design paved way for optimized weight. The dynamics of the capsule is obtained from the numerical analysis to ascertain the frequency and mode shape of both the structure and the fluid cavity. The stresses and displacement obtained in the static analysis qualified the model for stress clearance. Fluid structure interaction (FSI) study on the capsule highlighted the critical modes and frequencies of interest. Sound pressure level (SPL) and sound pressure inside the capsule is obtained for the external acoustic loads. The variation of SPL with respect to frequency inside the space capsule is plotted. The study helps in understanding the preliminary design requirements in developing a space capsule.
\end{abstract}

Keywords: Space capsule, Sound pressure level (SPL), Fluid structure interaction(FSI), Vibro-acoustic.

\section{INTRODUCTION}

Space capsule is a manned spacecraft which has a simple shape, without any wings and with other features to create lift during atmospheric reentry. It will carry the crew to space, provide emergency abort capability, sustain the crew and provide a safe return to Earth. The first manned space in the world used was Vostok by Russians [1] and currently a number of countries including USA, European Union [5], China [6] and India [2] have been developing manned space crafts. Manned space capsule's typical size is less than 5 meters in diameter. Capsule is volumetrically efficient and structurally strong, ablative heat shield is used for reentry and launching. Concept of using reusable capsule is to reduce the cost and same technology can be used for longer time with smaller modification in the structure. Capsules are ten time reusable with a replaceable heat shield.

The space capsule should take care of loads coming during its accent (blast off) and decent (re-entry) phases. Generally, the module is exposed to very high temperature $\left(1500^{\circ} \mathrm{c}\right)$ due to skin friction and also to high acoustic loads during reentry into earth's atmosphere. In the present work, a space capsule is optimally designed (geometrical features) to withstand loads such as gravity, and pressure. Both static and dynamics analysis has been performed on the capsule to validate the static and dynamic characteristics of individual components. Also, fluid structure interaction inside the capsule and the necessary Vibro-acoustic validity checks are performed. This presentation gives overall summary of the conceptual design and its validation.

\section{CAD MODELLING}

The typical geometrical features used in space capsule are derived from the open source [2], modifications to the existing dimensions are made where ever required based on the design requirements. A CAD (Computer Aided Design) model of the conceptual design is generated. The shape and the dimension of the space capsule is shown in the Figure 1.

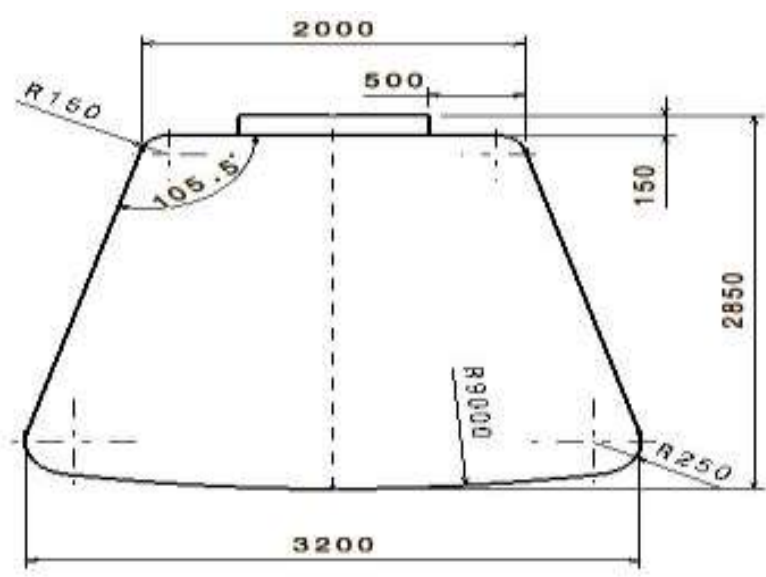

Figure 1: A 2d view of Space Capsule

The surface model of the capsule is developed in three stages. The first stage involves modelling the I-Section frames, inner crew cabin and outer skin that contains ceramic base $\&$ high temperature tiles. In the second and third stages, windows, doors, stiffened panel, inner skins and human seating base attachment frames were modelled, 
location for the doors and windows were chosen based on

the astronaut ergonomics.

Table 1: Material Properties used in the analysis

\begin{tabular}{|c|c|c|c|c|c|c|}
\hline $\begin{array}{c}\text { Sl } \\
\text { No. }\end{array}$ & Materials & E (MPa) & G (MPa) & $\rho\left(\text { Tons } / \mathrm{mm}^{3}\right)^{*} 10^{-}$ & $\mu$ & Temp ${ }^{\circ} \mathrm{C}$ \\
\hline 1 & LI-900 (TPS) & 169.12 & 116.31 & 1.4416 & 0.143 & 1200 \\
\hline 2 & LI-2200 (TPS) & 563.43 & 202.92 & 3.5241 & 0.388 & 1260 \\
\hline 3 & Inconel -718 & 98595.1 & 35162.3 & 82.20 & 0.402 & 1100 \\
\hline 4 & Inconel -625 & 14755.8 & 55219.9 & 84.42 & 0.336 & 900 \\
\hline 5 & Window glass & 72500 & 30980 & 22.03 & 0.17 & 700 \\
\hline 6 & $\mathrm{Al}$ 2024-T4 & 73100 & 27480 & 27.68 & 0.33 & 640 \\
\hline 7 & $\mathrm{Al}$ 2014-T6 & 73100 & 27480 & 27.95 & 0.33 & 640 \\
\hline 8 & Equivalent HSP & 1719.62 & 661.39 & 1.156 & 0.3 & 260 \\
\hline
\end{tabular}

The capsule consists of six I-section frames on which the entire outer skin with high temperature tiles, bottom skin with high density heat resistant tiles (can resist heat up to $2300^{\circ} \mathrm{C}$ ) and the inner stiffened crew chamber is fixed to it. A detailed configuration developed shown in the Figure 2: CAD model.

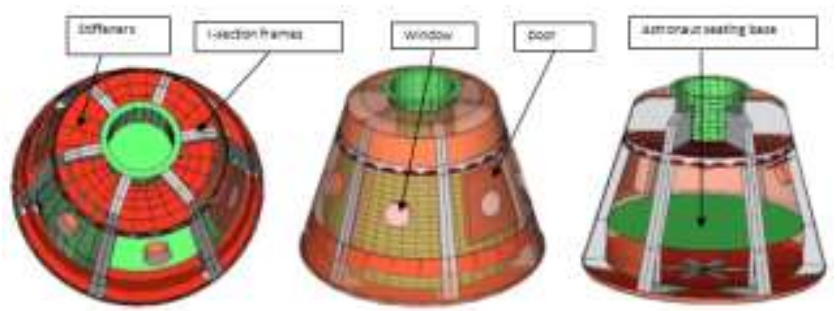

Figure 2:CAD Model

\section{MATERIALS PROPERTIES}

As the space capsule will be experiencing extreme environmental conditions, it is mandate for the designers to pick the right kind of materials for different parts of the capsule. The most important pre-requisite for a space capsule material is to with stand high temperatures up-to $2300^{\circ} \mathrm{C}$, have excellent resistance to a variety of corrosive media and have the ability to maintain its structural integrity in high temperature atmospheres. Hence the materials which satisfy all these requirements are INCONEL alloy 718 and 625 for external metallic structures and LI-900/LI-2200 Tiles for Thermal Protective System (TPS). Stiffened Aluminum 2024-T4, 2024-T6 are used for the crew compartment as it can help in weight reduction. Honeycomb sandwich panel (HSP) is used for the seating base which has aluminum core and face sheets. Details are shown in the table 1 .

\section{WEIGHT OPTIMIZATION}

During the design stage the structure both external and internal was considered to be made up of INCONEL alloy, because of this the weight of the capsule excluding the onboard equipment and the crew soared to 3.5 tones. Hence to reduce the weight, the internal structures where temperatures are low when compared to external structure have been replaced with Aluminum alloy 2024-T4/T6.With this combination of different material properties, weight has been optimized and therefore a weight reduction of 900 $\mathrm{kg}$ has been achieved.

\section{FINITE ELEMENT MODELLING}

The CAD surface model is considered for developing the finite element (FE) model. The axi-symmetricity of the model is taken as an advantage to reduce the time required for meshing the model. The model consist of six slices, only two slices are taken for meshing one with door and the other with window. HYPERMESH is used for developing the finite element model, QUAD and TRIA elements of MSC NASTRAN library are extensively used for the meshing. The FE model of the space capsule is shown in figure 3.
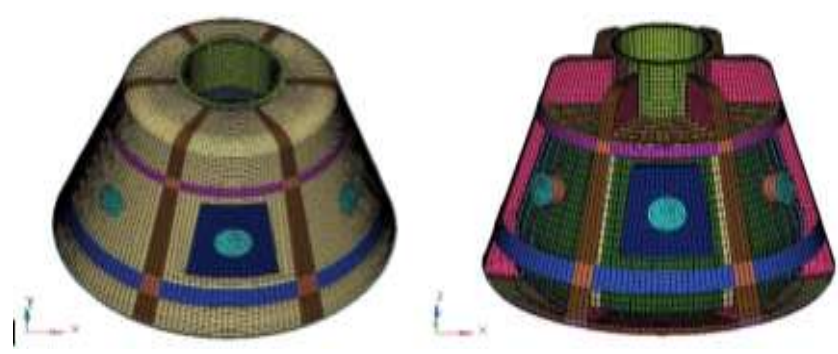

Figure 3: Finite Element Model

\section{STRUCTURAL ANALYSIS}

Strength and stiffness of the system are vital for any aerospace system. For model stress clearance with only gravity as load is considered for carrying out static analysis.

\section{STATIC ANALYSIS}

For the preliminary load calculation, a gravitational load of $3 \mathrm{~g}$ force is considered for static analysis. MSC NASTRAN solver is used to carry out the structural analysis; the required results like static displacement, Von Mises stress and strain are obtained (shown in figure 4 and table 2). 


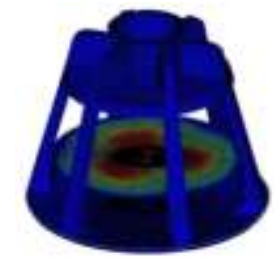

Displacement, $0.59 \mathrm{~mm}$

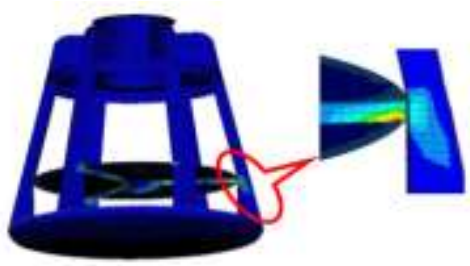

Von Mises Stress 3.87 MPa

Figure 4: Static Analysis

\section{NORMAL MODE ANALYSIS}

To obtain the dynamics of the structure, normal mode analysis is carried which gives the frequency and mode shape information of the structure and the six rigid body modes ensure the correctness of the FE model.

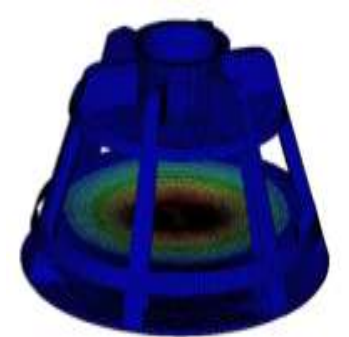

Mode 1, Freq. $63.79 \mathrm{~Hz}$

$88.61 \mathrm{~Hz}$

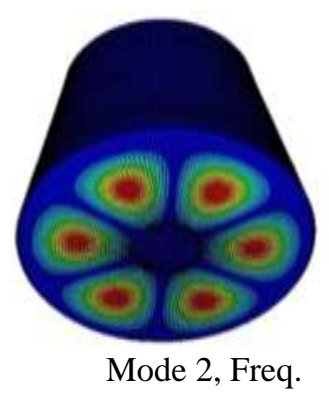

Figure 5: Mode shapes of the structure

Similarly, to obtain the mode shapes and frequencies of the fluid (air) inside the capsule; the normal mode analysis is carried which are shown in figure 6 and table3.

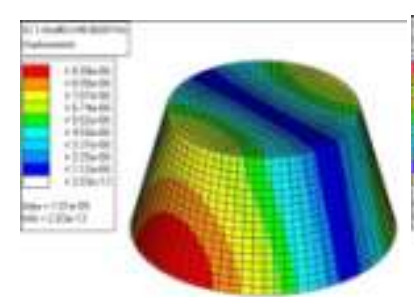

Mode 2, Freq. $88.8028 \mathrm{~Hz}$

$145.1855 \mathrm{~Hz}$

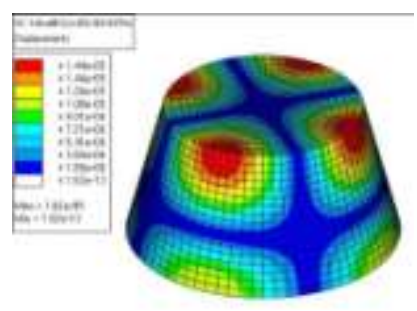

Mode 12, Freq. 203.9214Hz $54.0599 \mathrm{~Hz}$

Figure 6: Modes shapes of fluid inside capsule

\section{FLUID STRUCTURE INTERACTION (FSI) ANALYSIS}

The structural mode and fluid mode behave differently when they interact with each other. The FSI analysis helps the designers to find the critical modes which are capable of transmitting the structural vibrations to the fluid and vice versa. These interacting modes transmit the sound through vibration and thus leading to Vibro-acoustic [3] [7] problems inside the capsule. The structural interaction with fluid and the fluid's interaction with structure are shown in figure 7
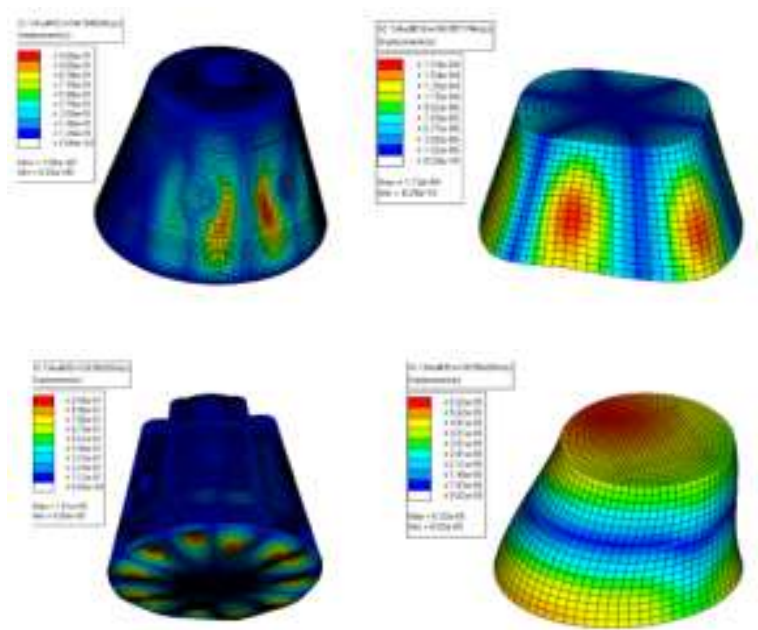

Figure 7: Fluid Structure Interaction (FSI) Analysis

\section{DETERMINATION OF SOUND PRESSURE}

\section{LEVEL (SPL)}

To determine the SPL inside the capsule, external acoustic source (noise source) [8] as an excitation pressure spectrum is applied on to the structure as Power Spectral Density (PSD) in terms of frequency and SPL, refer Figure 8(a). The sound transmitted into the structure is plotted in Figure $8(\mathrm{~b})$. Frequency range selected to extract the SPL result is between 10-260 Hz. The Maximum SPL and sound pressure contours are shown in figure 9.

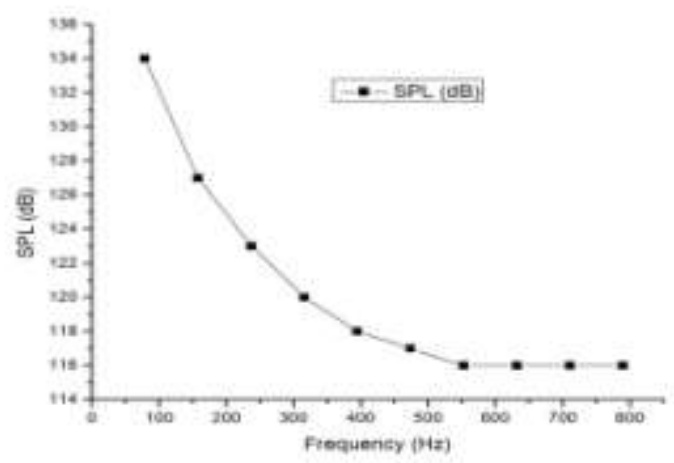

Figure 8(a): Excitation pressure spectrum [8] 


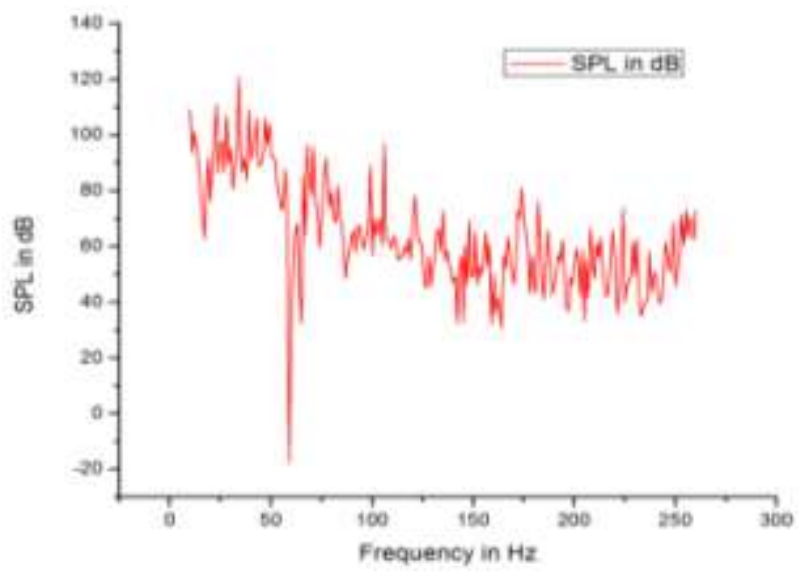

Figure 8(b): Sound pressure Level chart inside capsule From figure $8(\mathrm{~b})$ one can identify the variation in Sound Pressure Levels with frequency. The SPL and sound pressure contour plots for only two frequencies are shown in the figure 9,for the frequency 34 , the SPL level is $121 \mathrm{~dB}$ which is the maximum and for frequency 77 ,the SPL 91.8 $\mathrm{dB}$. The sound pressure contour inside the capsule is pictorially represented within the cross-section of the structure refer figure 10 .

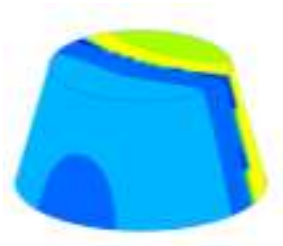

SPL: Freq. 34, $121 \mathrm{~dB}$

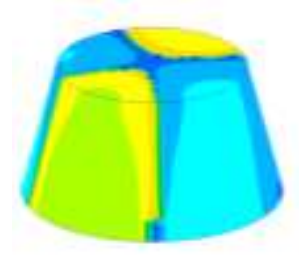

SPL: Freq. 77, $91.8 \mathrm{~dB}$

Figure 9: Sound Pressure level (SPL) / Sound Pressure (SP)

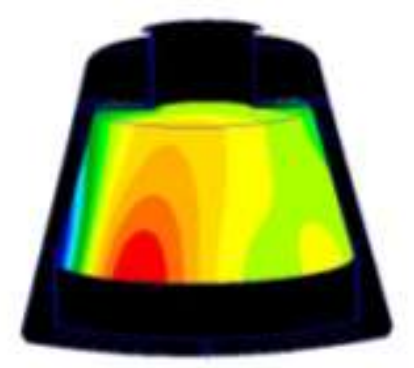

Figure 10: Sound Pressure inside c/s of space capsule

\begin{tabular}{|l|l|}
\hline \multicolumn{2}{|l|}{ Table 2: Static Analysis Results } \\
\hline Displacement $(\mathrm{mm})$ & 0.59 \\
\hline
\end{tabular}

\begin{tabular}{|l|l|}
\hline Von Mises Stress $(\mathrm{MPa})$ & 3.87 \\
\hline Von Mises Strain $(\mu)$ & 0.4 \\
\hline
\end{tabular}

\begin{tabular}{|c|c|c|c|c|}
\hline \multicolumn{5}{|c|}{ Dynamic Analysis results Table 3: } \\
\hline \multicolumn{2}{|c|}{$\begin{array}{l}\text { Normal modes of } \\
\text { Structure }\end{array}$} & \multicolumn{2}{|c|}{$\begin{array}{l}\text { Normal modes of } \\
\text { fluid }\end{array}$} & \\
\hline $\begin{array}{l}\text { Mod } \\
\text { e No }\end{array}$ & $\begin{array}{l}\text { Frequency }(\mathrm{Hz} \\
\text { ) }\end{array}$ & $\begin{array}{l}\text { Mod } \\
\text { e No }\end{array}$ & $\begin{array}{l}\text { Frequency }(\mathrm{Hz} \\
)\end{array}$ & $\begin{array}{l}\text { Literature } \\
{[4]}\end{array}$ \\
\hline 1 & 63.79 & 2 & 88.8028 & \multirow{4}{*}{$\begin{array}{l}45 \mathrm{~Hz} \\
\text { (launch } \\
\text { vehicle } \\
\text { frequency } \\
\text { ) }\end{array}$} \\
\hline 2 & 84.61 & 6 & 145.1855 & \\
\hline 3 & 88.03 & 12 & 203.9214 & \\
\hline 5 & 95.65 & 20 & 254.0599 & \\
\hline
\end{tabular}

\section{RESULTS AND CONCLUSIONS}

The results of static and dynamic analysis are tabulated in tables 2 and 3. From the static analysis, the displacement and Von Mises Stress are obtained and these are well below the critical values of the material, indicating that the conceptual design is safe. The dynamic analysis results are compared with that of literature [4]. From table 2, it is evident that the frequencies of the capsule are far above than the specified level. The SPL values obtained inside the capsule explains the variation of SPL with respect to frequency and highlights the highest noise level that is transmitted into the capsule. The numerical analysis reduces the cost and time in fabricating the real structure for initial and preliminary studies, which helps in designing the most efficient acoustic insulation inside the space capsule, this in turn protects the space crew / astronauts from dangerous acoustic loads which causes health hazards and may be fatal.

\section{REFERENCES}

[1]. Rex Hall, David Shayler (May 18, 2001) [1].The rocket men: Vostok \& Voskhod, the first Soviet manned spaceflights. Springer. p. 350

[2]. Www.space.com/5967-designs-manned-spaceshiprevieled.html [2].

[3]. A.Yarza et.al [3], Reflector vibroacoustic response to launch acoustic excitation, European Conference on Antennas and Propagation 2010, 12-16 April 2010, Barcelona

[4]. S. Ramakrishna [4], Polar Satellite Launch Vehicle User's Manual, Indian Space Research Organization Department of Space Government of India.

[5]. Nicholas L Johnson [5], Space technologies and space science activities of member states of the European Space Agency, California Institute of Technology by Kaman Sciences Corp., 1993.

[6]. China's Space Activities [6], The State Council Information Office, P.R.C., November, 2000.

[7]. Daisaku Inoyama et.al,[7] Vibro-Acoustic environnent for space vehicle, Orbital Sciences Corporation, Dulles, Virginia, 2016.

[8]. Jack E. Made, Donald W. Kurtz,[8] "A Review of Aerodynamic Noise From Propellers, Rofors, and LiffFans", Jet propulsion laborotary, California institute of technology, California, 1970. 